\title{
The Place of Voluntary Standards in Managing Social and Environmental Risks in Global Value Chains
}

\author{
Enrico PARTITI* (D)
}

Under the notion of human rights due diligence (HRDD), firms are under a responsibility to account for the social and environmental impact connected to their operations across global value chains. This responsibility intersects with the sphere of operation of voluntary sustainability standards (VSS), which certify production against certain social and environmental criteria. With mandatory European rules on HRDD in the making, the question arises regarding the extent of alignment of VSS with HRDD notions and, consequently, the possibility for this form of transnational private regulation to complement European Union (EU) HRDD legislation. After presenting the regulatory effects of HRDD in global value chains and its current transposition in EU instruments, this contribution examines the relationship between private standards and HRDD. By delving into the substantive requirements and policies of several schemes certifying agricultural commodities, this paper studies the extent to which they manage social and environmental risks in global value chains and the possible support they provide to firms subject to the upcoming HRDD obligations.

\section{INTRODUCTION}

Human rights violations and environmental impacts associated with business activities link consumers to harms such as breaches of labour rights, environmental damage or deforestation that take place in upstream value chain tiers located in foreign jurisdictions. For a long time, the firms committing them or enabling these negative impacts had impunity. At best, they were tackled under the notion of corporate social responsibility - identifying voluntary efforts by firms towards a restricted number of beneficiaries. ${ }^{1}$ The United Nations Guiding Principles on Business and Human Rights (UNGPs) affirmed instead a global and general expectation and a moral responsibility

\footnotetext{
* Assistant Professor of Transnational Regulation and Governance, Tilburg University, The Netherlands; Associate Researcher, T.M.C. Asser Institute, The Hague, The Netherlands; email: e.d.partiti@tilburguniversity.edu. This contribution was written in the context of a research project that received funding from the European Research Council (ERC) under the European Union's Horizon 2020 research and innovation programme (Grant Agreement No 725798).

1 United Nations, Office of the High Commissioner on Human Rights (2014) Frequently asked questions about the Guiding Principles on Business and Human Rights, 9-10.
} re-use, distribution, and reproduction in any medium, provided the original work is properly cited. 
for all corporations to respect human rights throughout their activities. ${ }^{2}$ The introduction of human rights due diligence (HRDD) as an integral component of the corporate responsibility of respect is among the most notable features of the UNGPs and one of the most consequential developments in the domain of responsible business conduct. HRDD covers all human rights potentially affected by business activities, and also environmental issues that negatively affect human rights, such as climate change ${ }^{3}$ or deforestation. ${ }^{4}$ HRDD thus holds considerable transformative potential for the ways in which businesses and corporations operate, for how they are structured internally and for how they manage a variety of economic and non-economic relationships and risks. HRDD defines and allocates precise responsibilities for business entities where they cause, contribute to or are directly linked to adverse human rights impacts in the entirety of their value chains. It prescribes risk management processes aimed at gathering information on, managing and mitigating social and environmental risks, as well as a collaborative approach among value chain entities in mitigating and remedying impacts. ${ }^{5}$

HRDD as a framework allocating responsibilities for harm and prescribing precise processes and various forms of across-the-chain collaboration has been conceptualised as a form of transnational law, intersecting with and impacting on the practices of private entities across the globe. ${ }^{6}$ The emergence of national legislation ${ }^{7}$ is making HRDD mandatory, with European Union (EU) measures currently in the making. ${ }^{8}$ These developments magnify the relevance of HRDD and its transformative effects not just for ensuring human rights compliance, but also for the ways in which firms manage, remedy and report on social and environmental risks. The implications of the UNGPs and HRDD have been assessed extensively from various human rights perspectives. ${ }^{9}$ However, the relationship between HRDD and various types of private regulators in the social and environmental domains remains entirely underexplored. While there is emerging research on how HRDD is operationalised internally by corporations and, generally, on how it affects them, ${ }^{10}$ it remains an open question as to how private regulatory initiatives and, in particular, voluntary sustainability standards (VSS) intersect and are aligned with HRDD.

2 Human Rights Council, “Guiding Principles on Business and Human Rights: Implementing the United Nations' 'Protect, Respect and Remedy“ Framework”, A/HRC/17/31 (21 March 2011) (UNGPs).

3 C Macchi, "The climate change dimension of business and human rights: the gradual consolidation of a concept of "climate due diligence"” (2021) 6 Business and Human Rights Journal 93.

4 E Partiti, "Private processes and public values. Tackling global deforestation and ecosystem conversation via nonfinancial due diligence" (forthcoming 2021) Transnational Environmental Law.

5 UNGPs, Principles 15-22.

6 K Buhmann, Changing Sustainability Norms through Communicative Processes: The Emergence of the Business \& Human Rights Regime as Transnational Law (Cheltenham, Edward Elgar 2017).

7 In France: Loi n ${ }^{\circ}$ 2017-399 du 27 mars 2017 relative au devoir de vigilance des sociétés mères et des entreprises donneuses d'ordre; Wet zorgplicht kinderarbeid, Stb. 2019, 401.

8 Introductory Remarks by Commissioner Phil Hogan at OECD Global Forum on Responsible Business Conduct, 19 May 2020, available at <https://ec.europa.eu/commission/commissioners/2019-2024/hogan/announcements/ introductory-remarks-commissioner-phil-hogan-oecd-global-forum-responsible-business-conduct_en > .

9 S Deva and D Bilchitz (eds), Human Rights Obligations of Business: Beyond the Corporate Responsibility to Respect? (Cambridge, Cambridge University Press 2013).

10 D Monciardini, N Bernaz and A Andhov, "The organisational dynamics of compliance with the UK Modern Slavery Act in the food and tobacco sector" (2021) 60 Business \& Society 288. 
VSS define and enforce through certification the social and environmental characteristics of production and products in domains as diverse as raw materials, agricultural commodities and textile products. ${ }^{11}$ VSS result in standards that are set and managed by multi-stakeholder and sectoral organisations and are then voluntarily complied with by producers under the promise of a market premium, better risk management or improved reputation. As a form of transnational private governance applicable to the firms and producers that wish to comply, VSS hold potential for supporting firms in operationalising and diffusing HRDD-compliant requirements among certified businesses and their value chains. VSS refer to international law and soft law provisions in the social and environmental domains. They provide tools that allow producers to directly comply with these obligations, as well as forms of monitoring and enforcement via audit. VSS are thus in a relationship of regulatory complementarity to these rules, potentially supporting their operationalisation at the firm level. ${ }^{12}$ Arguably, this happens by design, so that they can help firms towards legal compliance and in managing their social and environmental risks. But to what extent do VSS intersect with HRDD constructs and responsibilities, and to what extent could they support companies' compliance with future HRDD obligations?

Potentially, VSS relate to HRDD in two ways. In the first instance, standards defining responsible production and sourcing contain both substantive and procedural criteria defining and verifying social and environmental characteristics of products and their production across value chain actors. Under proper monitoring and enforcement, they can thus represent evidence of low social and environmental risk. It is, however, essential to understand how VSS address various risks and which ones they address, how they monitor and enforce their requirements and what segments of a value chain are covered. This paper focuses in particular on private standards that certify forestry products and agricultural commodities in light of concerns connected to the conversion of natural forests and ecosystems and associated human rights violations. These schemes apply to different groups of producers and offer various forms of chain of custody certification open to firms other than producers. Standards thus apply to several entities in a value chain. In this way, standards offer the possibility to operationalise not just the due diligence responsibilities of producers outside the EU, but also the obligations of downstream entities marketing or established in jurisdictions where HRDD legislation is present or forthcoming and the accounting of all business relationships that these firms have in a given (segment) of the value chain.

Clarifying the relationship between VSS and HRDD would allow us to better understand a possible function of private standards in HRDD legislation under discussion in the EU, as well as their limitations. This article thus contributes to the debate on mandatory HRDD in the EU and the place of private standards therein. As it discusses VSS against the general constructs of the UNGPs, this analysis is relevant

\footnotetext{
11 See generally: A Marx and J Wouters, "Competition and cooperation in the market of voluntary sustainability standards" in P Delimatsis (ed.), The Law, Economics and Politics of International Standardisation (Cambridge, Cambridge University Press 2015) p 215.

12 E Partiti, "Orchestration as a form of public action: the EU engagement with voluntary sustainability standards" (2019) 25 European Law Journal 115-16. On the complementarity of transnational private regulation, see F Cafaggi, "New foundations of transnational private regulation" (2011) 38 Journal of Law and Society 20.
} 
regardless of the form of EU mandatory intervention in the area of HRDD - as long as this is aligned with the notions in the UNGPs. This paper is structured as follows: Section II presents the main features of HRDD and discusses the general features of VSS. Informed by previous forms of public use of VSS in EU legislation, Section III discusses the recent legislative proposals by the EU Parliament on mandatory HRDD and a possible role for private standards. Section IV opens up the black box of VSS and illustrates how schemes align with HRDD notions of full value chain coverage and risk mitigation. It does so by studying the VSS requirements contained in production standards, codes of conduct, documents and policies from seven schemes and meta-regulators in the domains of timber, palm oil, soy, sugarcane, cocoa and coffee certification, as well as nongovernmental organisation (NGO) reports. A series of semi-structured interviews with NGO representatives and certification managers shed further light on VSS' functioning. Section V looks at collaborative approaches in risk mitigation and, generally, remediation of social and environmental harms through VSS. Section VI concludes.

\section{Due diligence in Global value chains}

Human rights violations connected to transnational corporations remain some of the most difficult-to-eradicate negative consequences of globalisation. The 2011 adoption of the Respect, Protect, Remedy Framework ${ }^{13}$ and its operationalisation in the UNGPs was almost unanimously welcomed as one of the main successes in this domain. The UNGPs embrace private corporate processes, risk assessment tools and management systems to manage externalities and risks connected to the human rights impacts of businesses. In addition to the State duty to protect against human rights abuses, a corporate responsibility to respect human rights is established, parallel to a third pillar affirming a right to remedy for human rights violations. Corporations should actively assess human rights risks in all of their activities, act upon the findings of their information-gathering efforts and communicate to the public regarding their impact on human rights. HRDD also requires firms to remedy their impacts and offer venues to right holders for this purpose. Section II.1 elucidates the main features of HRDD as provided in the UNGPs. These features are particularly relevant for EU regulatory initiatives making HRDD mandatory, as the current proposals are aligned to the notions in the UNGPs. Section II.2 illustrates the main aspects of VSS and their use by firms.

\section{The main features of HRDD}

HRDD incorporates human rights at the heart of firms' management processes. HRDD constitutes "an ongoing management process that a reasonable and prudent enterprise needs to undertake, in the light of its circumstances (including sector, operating

13 Human Rights Council Res. 8/7, U.N. DOC. A/C/RES/8/7 (18 June 2008). 
context, size and similar factors) to meet its responsibility to respect human rights". ${ }^{14}$ In addition to the publication of a policy commitment and ensuring remediation, HRDD as described in the UNGPs requires all firms to undertake a human rights impact assessment, integrating its findings in corporate procedures, tracking responses and communicating to the broader public. HRDD defines and allocates precise responsibilities for business entities where they cause, contribute to or are directly linked to adverse human rights impacts in their value chains. In the first two cases, a firm should stop generating adverse impacts and offer remediation to those harmed. The notion of corporate responsibility in the UNGPs is traceable to the emergence of business practices accepting and institutionalising a "duty of care" towards affiliates. ${ }^{15}$ The UNGPs, however, extend such a duty of care from the narrower relation between a parent company and a subsidiary to all human rights impacts stemming from commercial and non-commercial relations that a corporation has with other business entities, employees, customers, and human rights holders affected by operations. Where a firm is directly linked to adverse impacts through a commercial relationship, leverage should be exercised to ensure that the entity to which it is linked ceases and remedies the harm, including in collaboration with other firms and stakeholders, and ultimately disengages if this does not occur. ${ }^{16}$

Through the key notion of direct link, the UNGPs ask corporations to address via HRDD impacts that are considerably broader than those connected to their immediate actions and operations. Such requirements should apply to all entities in a global value chain, as HRDD responsibility goes beyond direct contractual relations with suppliers, ${ }^{17}$ therefore linking up downstream firms all the way to upstream producers where raw materials are extracted and produced, as well as all intermediary actors. This also is connected to value chain transparency, which is in fact a prerequisite for responsible business conduct as also clarified in relevant international standards. HRDD is intimately connected with value chain management and, generally, selfgovernance of economic activities. ${ }^{18}$ Through HRDD constructs, firms are required to act as a transnational value chain (self-)regulator/enforcer in the domain of human rights. ${ }^{19}$ Corporations have to design procedures to monitor their human rights impacts and to ensure that human rights are respected throughout their activities and business relations in their value chain. Especially in the two cases of "contribution" and "direct link", this regulatory function includes the creation of strategies to engage with other entities and leverage them and ultimately "sanction" non-complying suppliers with disengagement.

\footnotetext{
14 Office of the High Commissioner on Human Rights (2012) The corporate responsibility to respect human rights. An interpretative guide. HR/PUB/12/02, 6.

15 R Mares, "Global corporate social responsibility, human rights and the law: an interactive regulatory perspective on the voluntary-mandatory dichotomy" (2010) 1 Transnational Legal Theory 212.

16 UNGPs, Principle 17. For a discussion of the three categories for involvement, their regulatory effects and their interpretation in international soft law, see E Partiti, "Polycentricity and polyphony in international law. Interpreting the corporate responsibility to respect human rights" (2021) 70(1) International and Comparative Law Quarterly 133-64. 17 UNGPs Principle 19 and commentary.

18 H Hofmann, MC Schleper and C Blome, "Conflict minerals and value chain due diligence: an explanatory study of multi-tier value chains" (2018) 147 Journal of Business Ethics 115.

19 GA Sarfaty, "Shining light on global value chains" (2015) 56 Harvard International Law Journal 419.
} 
This sui generis conferral of regulatory functions across value chains is enabled and circumscribed by procedural and process requirements. To meet the UNGPs, corporations have to adopt, design and continuously assess, evaluate and improve risk-based processes that, in the relation with other entities, are engrained in value chain management systems. ${ }^{20}$ HRDD presents typical elements of risk management requiring firms to identify, assess and mitigate risks. ${ }^{21}$ Upon the performance of a human rights impact assessment, HRDD management systems must provide businesses with information on human rights risks, allow them to evaluate the presence of risk, act upon the findings by devising means to reduce risks, integrate the findings into corporate procedures and track responses. In addition, a policy commitment to respect human rights should be adopted by the firm, internal remediation mechanisms must be offered and firms must communicate and report to the public about their social and environmental performance. ${ }^{22}$ Risks covered by HRDD are not financial or reputational risks for the firm concerned, but rather encompass the risk that human rights are negatively impacted by business activities. ${ }^{23}$ HRDD therefore plays a crucial role in the identification, prevention, assessment and cessation of adverse social and environmental impacts. ${ }^{24}$

The UNGPs also require meaningful consultations with potentially affected groups and other stakeholders in identifying and assessing actual and potential adverse impacts ${ }^{25}$ and remedy mechanisms, thereby offering tools to give regard to the interests of those affected by firms' activities. ${ }^{26}$ While performing HRDD, firms are required to actively engage vertically and horizontally with other enterprises in order to address general and specific human rights impacts. ${ }^{27}$ HRDD therefore aims to move beyond compliance-based forms of private regulation of global value chains, whose effectiveness has been questioned particularly in the area of working conditions. While not abandoning entirely compliance-based strategies, HRDD is aligned with a commitment-based approach, where firms cooperate to improve practices via joint problem-solving, which has been observed to be more effective for enabling change. ${ }^{28}$

\section{Voluntary sustainability standards and their use by firms}

Voluntary standards achieved considerable business uptake in ensuring social and environmental sustainability across value chains. Well-known initiatives such as the Forest Stewardship Council (FSC), the Programme for the Endorsement of Forest Certification (PEFC), the Roundtable on Responsible Palm Oil (RSPO), the

20 UNGPs Principles 15 and 17.

21 For operationalisation: ISO (2018) ISO 31000:2019. Risk management guidelines.

22 UNGPs Principle 17.

23 Commentary to UNGP 17.

24 UNGPs Principles 16 and 17.

25 UNPGs Principle 18.

26 E Partiti, "Trust in global governance. Ensuring trustworthiness of transnational private regulation" (2020) 52 NYU Journal of International Law and Politics 466-68.

27 UNGPs Principle 18.

28 RM Locke, The Promise and Perils of Private Power: Promoting Labour Standards in a Global Economy (Cambridge, Cambridge University Press 2013). 
Rainforest Alliance (RA)-UTZ, Fairtrade and many others bring to the fore the function of multi-stakeholder and business organisations in coordinating and regulating the sustainability characteristics of global production. Third-party auditing and, increasingly, the use of technologies such as satellite images and remote sensing in the deforestation space contribute to monitoring and enforcing compliance. However, quantifying the effectiveness and impact of VSS remains complex and debated. ${ }^{29}$ There are deeply rooted structural problems that can only be solved with the involvement of all relevant public and private actors, as well as mandatory rules.

Private standards are also not immune to the power imbalances in a value chain, and they reproduce and contribute to further asymmetries in power and resources. ${ }^{30}$ These initiatives are often led by Western economic interests, but are then mostly applied in the Global South, thereby limiting the possibility for the effective representation of affected interests. The governance of VSS organisations rarely includes farm workers, smallholders and indigenous communities effectively in standard-setting and decisionmaking. ${ }^{31}$ Private regimes also rarely challenge a dominant narrative that trade and market mechanisms can deliver sustainability. ${ }^{32}$ Private regimes have proliferated - a situation that complicates implementation by firms and generates negative implications for trade. ${ }^{33}$ Trade barrier effects of VSS have been denounced for many years by developing countries, ${ }^{34}$ especially at the World Trade Organization (WTO). ${ }^{35}$ VSS requirements are complex and burdensome to implement, especially for small producers. Where requested by lead retailers, VSS can become a de facto necessary condition not just to enter their value chain, but also to market in Western countries. ${ }^{36}$ However, the WTO discipline of private standards remains elusive at best. ${ }^{37}$ VSS organisations are also very different and may represent only industry or attempt to include the interests of affected actors and civil society. ${ }^{38}$ The standards that have emerged therefore vary greatly and offer margins to firms to shop for requirements that better fit their needs or that are simply less demanding.

\footnotetext{
29 UNFSS (2018) Voluntary sustainability standards, trade and sustainable development. 3rd Flagship Report of the United Nations Forum on Sustainability Standards (UNFSS).

30 See generally B Daviron and S Ponte, The Coffee Paradox: Global Markets, Commodity Trade and the Elusive Promise of Development (London, Zed Books 2005).

31 EA Bennett, "Who governs socially-oriented voluntary sustainability standards? Not the producers of certified products" (2017) 91 World Development 53.

32 J Clapp, "The trade-ification of the food sustainability agenda" (2016) 44 Journal of Peasant Studies 335.

33 L Fransen, "Multi-stakeholder governance and voluntary programme interactions: legitimation politics in the institutional design of corporate social responsibility" (2012) 10 Socio-Economic Review 163.

34 SW Chang, "GATTing a green trade barrier. Eco-labelling and the WTO Agreement on Technical Barriers to Trade" (1997) 31 Journal of World Trade 137; M Joshi, "Are eco-labels consistent with World Trade Organisation Agreements?" (2004) 38 Journal of World Trade 69.

35 Committee on Sanitary and Phytosanitary Measures, Note by the WTO Secretariat: Summary of the SPS Committee Meeting of 29-30 June 2005 G/SPS/R/37.

36 S Henson and J Humphrey, "The impact of private food safety standards on the food chain and on public standardsetting processes". Paper Prepared for FAO/WHO Codex Alimentarius Commission (2009).

37 PC Mavroidis and R Wolfe, "Private standards and the WTO. Reclusive no more" (2017) 16 World Trade Review 1.

38 In the domain of timber certification, see T Cadman, Quality and Legitimacy of Global Governance. Case Lessons
} from Forestry (London, Palgrave Macmillan 2011). 
Both to gain legitimacy from their association with public norms and to increase uptake by firms, VSS requirements are often linked to national and international provisions in the social and environmental domains. ${ }^{39}$ Standards specify the details of responsible working practices in a given sector, country or factory or what activities would result in the sustainable exploitation and management of natural resources. From a functional perspective, VSS' regulatory activity has the effect of transforming broad environmental and social norms into applicable rules. It is, however, necessary to closely scrutinise the contents of standards in order to appraise their actual alignment with international provisions. Codes and standards ensuring responsible working practices in the garment sector have been observed to include only selected provisions in the relevant International Labour Organization's (ILO) Conventions, rarely covering subjects such as maximum working hours. ${ }^{40}$ In addition to substantive requirements concerning, for example, working conditions or land conversion, private standards have over time strengthened the provision of procedural requirements for value chain management. As companies need tools to operationalise HRDD in their activities, and also in light of national legislation, VSS aligned their requirements and introduced new ones to operationalise HRDD and thus enhance their potential complementarity to international soft law tools such as the UNGPs and various Organisation for Economic Co-operation and Development (OECD) Guidance documents.

Firms must monitor and regulate commercial relations in a value chain to ensure coordination across functional units throughout the globe. Value chain management systems assess the actual and potential impacts of a firm's activities on various economic and non-economic risks, including plans to manage and monitor impacts, with regular evaluation of their effectiveness and performance improvement. ${ }^{41}$ Sustainability management tools address and manage sustainability practices and risks not just of the (downstream) firm implementing the system, but also of suppliers and sub-suppliers. ${ }^{42}$ Sustainability value chain management includes monitoring and sanctioning the obligations determining the conditions for entry and exit from a value chain up until the remotest upstream tiers. ${ }^{43}$ It also requires reporting, investigating and remedying (potential) instances of non-compliance - including by the suppliers of a supplier. ${ }^{44}$ From the perspective of firms, VSS are additional tools through which they govern their value chains and manage social and environmental impacts and the

\footnotetext{
39 Partiti, supra, note 12, 97.

40 P Paiement and S Melchers, "Finding international law in private governance: how codes of conduct in the apparel industry refer to international instruments" (2020) 27 Indiana Journal of Global Legal Studies 303.

41 E Meidinger, "Governance interactions in sustainable value chain management" in S Wood, R Schmidt, E Meidinger, B Eberlein and KW Abbott (eds), Transnational Business Governance Interactions. Advancing Marginalised Actors and Enhancing Regulatory Quality (Cheltenham, Edward Elgar 2019) p 58.

42 T Thorlakson, JF de Zegher and EF Lambin, "Companies' contribution to sustainability through global value chains" (2018) 115 Proceedings of the National Academy of Sciences of the United States of America 2072.

43 MP Vandenbergh, "The new Wal-Mart effect: the role of private contracting in global governance" (2007) 54 UCLA Law Review 917.

44 F Cafaggi, "Regulation through contracts: supply-chain contracting and sustainability standards" (2016) 12 European Review of Contract Law 228.
} 
associated financial and non-financial risks. ${ }^{45}$ VSS are thus far from being only an instrument for consumers to distinguish sustainable from non-sustainable products or a way for firms to deflect "naming and shaming" campaigns. ${ }^{46}$ They also allow firms to avoid costs, achieve a competitive advantage and manage their value chains through their use and embedding in value chain management, to define the rights and obligations of various entities and to implement due diligence and legality requirements. ${ }^{47}$ VSS processes are thus integrated within firms' management practices. ${ }^{48}$

Compliance with VSS is monitored and enforced through third-party auditing. Auditing brings a third party in to assess compliance, but it is exposed to various challenges. Third-party auditing operates under the presumption that auditors can operate independently from the firms paying for their services, but this is hardly the case in the presence of conflicts of interest - since auditors are paid by the firms seeking certification. Auditing is also practically complex to undertake in many of the contexts where VSS operate, and its success depends on the technical capacity of the auditors to identify non-compliance. ${ }^{49}$ Auditors also certify compliance with VSS requirements in situations where this would be dubious. They have been found to routinely certify compliance against ILO requirements, including freedom of association, in countries such as China or Vietnam, where free trade unions are not allowed. ${ }^{50}$ VSS may possibly contain strong standards and criteria, but the shortcomings of auditing could considerably hinder their implementation and effectiveness.

\section{EU MANDATORY HRDD MEASURES AND THEIR RELATIONSHIP WITH VSS}

The due diligence legislation currently discussed in the EU is based on an EU Parliament's proposal on a corporate due diligence and corporate accountability Directive, ${ }^{51}$ with possible specific rules for agricultural commodities and ecosystem conversion as indicated by the EU Parliament's proposal on an EU legal framework to halt and reverse EU-driven global deforestation. ${ }^{52}$ These proposals require undertakings falling under the scope of conducting due diligence throughout such firms' value chains and accounting for impacts that they caused or contributed to or to which they are directly linked. The obligation of due diligence requires firms to

\footnotetext{
45 S Ponte, "Green capital accumulation: business and sustainability management in a world of global value chains" (2020) 25 New Political Economy 73.

46 P Dauvergne, "Is the power of brand-focused activism rising? The case of tropical deforestation" (2017) 26 Journal of Environment \& Development 135.

47 T Bartley, "Transnational governance and the re-centred state: sustainability or legality" (2014) 8 Regulation \& Governance 93.

48 Cafaggi, supra, note 44.

49 RM Locke, M Amengual and A Mangla, "Virtue out of necessity? Compliance, commitment, and the improvement of labor conditions in global value chains" (2009) 37 Politics \& Society 319.

50 P Paiement, "Jurisgenerative role of auditors in transnational labour governance" (2019) 13 Regulation \& Governance 280 .

51 European Parliament, Draft report of 11 September 2020 with recommendations to the Commission on corporate due diligence and corporate accountability (2020/2129(INL)).

52 European Parliament, Draft motion of 15 June 2020 for an EU Parliament Resolution with recommendations to the Commission on an EU legal framework to halt and reverse EU-driven global deforestation (2020/2006(INL)).
} 
identify, assess, prevent, cease, mitigate, monitor, communicate, account for, address and remedy potential and actual adverse impacts, combined with a stakeholder engagement requirement and the establishment of firm-level grievance mechanisms. Both initiatives establish liability and sanctioning regimes, as well as various forms of monitoring for firms' impacts and the proper establishment and operation of HRDD systems. The proposal on deforestation also includes definitional criteria for deforestation and ecosystem conversions, as well as an obligation to place on the market only products that, after conducting HRDD, present negligible risks.

Mandatory HRDD will thus require firms to have access to information about all possible human rights and environmental risks in their value chains. It establishes an obligation to set up risk assessment procedures allowing firms to evaluate the risk that adverse human rights impacts occur in value chains. In the presence of nonnegligible risk, risk mitigation procedures must be established to minimise and eliminate such risk. Both proposals thus mirror the notions and approach prescribed by international soft law instruments such as the UNGPs and their transposition in various sector-specific OECD Guidance documents requiring firms to account for the entirety of adverse social and environmental impacts that they caused, to which they contributed or to which they are directly linked through their business relations. The EU Conflict Mineral Regulation - currently the only EU measure establishing mandatory HRDD in a narrow sector and for a limited number of transactions - is also aligned to international soft law instruments on HRDD. ${ }^{53}$ There are, however, reports of extensive lobbying aiming to narrow down the scope of due diligence to first-tier suppliers. ${ }^{54}$ This would not just be against the requirements of the UNGPs and the OECD Guidelines, which the EU is under an obligation to support, ${ }^{55}$ but would also allow considerable loopholes through which firms could evade their responsibilities.

Within these due diligence-based legislative initiatives, and generally with respect to businesses' responsibility to exercise HRDD, the possible function of VSS must be carefully unpacked. Public support for sustainability standards increases where schemes can successfully assist public authority in domestic policies. ${ }^{56}$ Under certain conditions, these schemes can support public action. This occurs especially when certification can assist in monitoring compliance with requirements in jurisdictions where public authorities would not have the capacity nor the authority to do so, thereby allowing the extraterritorial implementation of public criteria. VSS are thus a complement to and not a replacement of public governance. This is also the position

\footnotetext{
53 Regulation (EU) 2017/821 of the European Parliament and the Council of 17 May 2017 laying down value chain due diligence obligations for Union importers of tin, tantalum and tungsten, their ores, and gold originating from conflictaffected and high-risk areas. OJ L 130/1, Art 4.

$54 \mathrm{~K}$ van Teffelen, "Obstruct, delay, weaken. The lobby by VNO-NCW against legislation on corporate accountability" (SOMO, 21 May 2021) <https://www.somo.nl/obstruct-delay-weaken/>.

55 For the UNGPs: United Nations. Office of the High Commissioner on Human Rights (2014) Frequently asked questions about the Guiding Principles on Business and Human Rights. HR/PUB/14/3. For the OECD Guidelines, see OECD Legal Instruments at <https://www.oecd.org/legal/legal-instruments.htm>. The concept is also reaffirmed in the Foreword to the various OECD Guidance documents.

56 B Cashore and M Stone, "Does California need Delaware? Explaining Indonesian, Chinese, and United States support for legality compliance of internationally traded products" (2014) 8 Regulation \& Governance 59.
} 
explicitly taken by some VSS in public consultations. ${ }^{57}$ Standard are, however, not just useful in the monitoring and enforcement stages. Schemes' implementing functions are also appealing to public authority and have been used to specify detailed features of sustainable products, such as in public procurement. ${ }^{58}$ Relevant to the emergence of mandatory HRDD legislation, VSS also specify the procedural requirements, steps and appropriate actions that firms must take in the context of HRDD.

The EU Timber Regulation in an example of a previous mandatory intervention addressing value chains, establishing a due diligence obligation for timber legality and prescribing relevant features of value chain management tools that firms must adopt to ensure that only legal timber is handled. It limited the role of VSS to nondispositive evidence of compliance in the context of firms' access to information requirements in risk management ${ }^{59}$ and in the context of risk assessment and risk mitigation. ${ }^{60}$ This means that certification can be used as a relevant tool to gain access and identify relevant information about risk profiles and that certification can contribute to mitigate risks. This narrow approach seems to be retained in the current proposals by the EU Parliament. In its initiative on deforestation, the Parliament noted that while third-party certification schemes played an important role in bringing together business and civil society to develop a common understanding of global deforestation, such schemes alone cannot halt and reverse it.

The Parliament highlighted the complementary role of VSS to binding measures, and also to firms' due diligence. This would occur only where schemes contain well-defined, measurable and ambitious sustainability criteria aligned to EU standards and provide for a robust certification and accreditation process, independent monitoring and compliance mechanisms and possibilities to monitor the value chain. ${ }^{61}$ The Parliament also called upon the Commission to establish criteria to assess the credibility of VSS, including independence from industry, the inclusion of social and environmental interests in standard-setting, independent third-party auditing, public disclosure of auditing reports, transparency and openness. In light of the close association of some schemes with industry, these requirements are indispensable for ensuring that only trustworthy schemes are used by firms. These conditions are based on and would go beyond those contemplated under the Public Procurement Directive, which arguably prescribes the strictest conditions for VSS use of all EU measures that allow their employment. ${ }^{62}$ They also go beyond current Commission practice in the context of

\footnotetext{
57 See the FSC submission to the evaluation and fitness check for the European Union Timber Regulation (EUTR) and the Forest Law Enforcement, Governance and Trade (FLEGT) regime: <https://ec.europa.eu/info/law/betterregulation/have-your-say/initiatives/11630-Illegal-logging-evaluation-of-EU-rules-fitness-check-/F506597>.

58 Directive 2014/24/EU of the European Parliament and of the Council of 26 February 2014 on public procurement. OJ L 94/65, Arts 42 and 43 and Annex VII.

59 Regulation (EU) No. 995/2010 of the European Parliament and the Council of 11 May 2009 laying down the obligations of operators who place timber and timber products on the market. OJ L 295/13, Recital 19, Arts 6(1)(b) and $6(1)(\mathrm{c})$.

60 Commission Implementing Regulation No 607/2012 of 6 July 2012 on the detailed rules concerning the due diligence system and the frequency and nature of the checks on monitoring organisations as provided for in Regulation (EU) No 995/2010 OJ L 177/16, Art 4.

61 European Parliament resolution of 22 October 2020 with recommendations to the Commission on an EU legal framework to halt and reverse EU-driven global deforestation (2020/2006(INL)), paras 14-17.

62 Partiti, supra note 12.
} 
the Conflict Minerals Regulation, where private schemes can be used - however, not by firms marketing in the EU, but by non-EU-based smelters. Here, the criteria for recognition mostly encompass a substantive alignment of VSS in the domain of minerals certification with the relevant OECD Guidance, with less of a focus on governance criteria. ${ }^{63}$ The EU Parliament also stressed that use of VSS must not affect a firm's liability for possible breaches. ${ }^{64}$ The EU Parliament's resolution for an across-the-board HRDD Directive shares the same approach towards private standards. ${ }^{65}$

It seems that the EU institutions are unwilling to repeat the experience of the Renewable Energy Directive, where compliance with formally recognised schemes gives rise to a presumption of conformity with the substantive sustainability requirements indicated in a legal instrument. ${ }^{66}$ This approach - and especially the extent of the Commission's supervision over the schemes, a lenient appraisal in their selection and the lack of human rights requirements included in the recognised schemes - was extensively criticised by the Court of Auditors. ${ }^{67}$ While formal recognition of VSS is possible under the Conflict Minerals Regulation and the recent Commission proposal on sustainable batteries, ${ }^{68}$ this form of recognition with respect to HRDD procedures only grants undertakings a way to comply with obligations concerning the presence of due diligence systems, but not their effective operation and, ultimately, human rights impacts. Under the Conflict Minerals Regulation, Member States can impose sanctions, and civil liability remains a possibility for violations that constitute unlawful acts towards third parties. ${ }^{69}$ As a consequence, a firm's compliance with a VSS would not grant a firm with a presumption of conformity with HRDD legislation or immunity from litigation and sanctions, but would serve firms as a risk mitigation tool capable of producing rebuttable evidence of "low risk" - provided that the scheme used is aligned with the requirements of the measure in question. Use of VSS as a "safe harbour" in compliance with HRDD would contradict the UNGPs' focus on the active and continuous performance of due diligence, as well as stakeholder inclusion and consultation. ${ }^{70}$

In light of the risk management function of VSS, regardless of formal recognition and a presumption of conformity, mandatory HRDD arguably incentivises their use as a part of

63 Commission Delegated Regulation (EU) 2019/429 of 11 January 2019 supplementing Regulation (EU) 2017/821 of the European Parliament and of the Council as regards the methodology and criteria for the assessment and recognition of value chain due diligence schemes concerning tin, tantalum, tungsten and gold. L 75/59.

64 European Parliament resolution of 22 October 2020 with recommendations to the Commission on an EU legal framework to halt and reverse EU-driven global deforestation (2020/2006(INL), p 32.

65 European Parliament resolution of 10 March 2021 with recommendations to the Commission on corporate due diligence and corporate accountability (2020/2129(INL)), Annex, recital 35.

66 Directive (EU) 2018/2001 of the European Parliament and of the Council of 11 December 2018 on the promotion of the use of energy from renewable sources OJ L 328, Arts 30.4, 30.5 and 30.7.

67 European Court of Auditors (2016) The EU system for the certification of sustainable biofuels: <https://www.eca. europa.eu/Lists/ECADocuments/SR16_18/SR_BIOFUELS_EN.pdf >.

68 Commission Proposal for a Regulation concerning batteries and waste batteries, COM(2020) 798/3 2020/353 (COD), p 68.

69 ME Footer, "The EU's engagement with business on human rights" in J Wouters, M Nowak, AL Chané and N Hachez (eds), The European Union and Human Rights: Law and Policy (Cambridge, Cambridge University Press, 2020) p 319.

70 L Smit and C Bright, "The concept of a 'safe harbour' and mandatory human rights due diligence" (2020) CEDIS Working Paper December 2020. 
companies' responsibilities and obligations by giving firms a tool to show that they "do not harm" and to monitor progress and improvements. Both Parliament proposals create, in line with the UNGPs, obligations of value chain transparency that certification schemes could be well placed to offer. VSS are, however, not the only existing tool that can exercise these functions. Private business programmes designed in the context of internal sustainability value chain management operate in various sectors covered by VSS. ${ }^{71}$ In connection with deforestation, alternative forms of private governance have emerged. Multi-party pledges such as the Brazilian Soy Moratorium include public enforcement and strong enforcement mechanisms to avoid the trading of non-compliant products, and thus they also contribute to ensuring and demonstrating a low risk of at least certain human rights impacts.

\section{SOCIAL AND ENVIRONMENTAL RISK MANAGEMENT THROUGH STANDARDS}

With the emergence of mandatory HRDD, VSS are capable of supporting firms in consuming countries to demonstrate compliance with due diligence obligations only to the extent of their alignment with HRDD constructs. Generally, a scheme's requirements must be aligned to HRDD as provided in the UNGPs, various OECD Guidelines and the specifications of due diligence as indicated in future regulatory instruments in order for a scheme to be of assistance in firms' due diligence responsibilities. In the presence of alignment between the issues and risks covered by a VSS and faced by a firm, standards are potentially suitable for integration into that firm's HRDD processes. The broader the alignment, as well as regarding its value chain scope, the more a scheme covers the extent of a firm's HRDD responsibilities and obligations. The effectiveness of VSS as risk mitigation tools also depends closely on the extent to which a given social and environmental concern or harm can be detected and whether third-party audit and certification is capable of verifying and ensuring that the scheme's criteria are implemented properly.

Certification has been described as a regulatory technique under which information is provided to firms and consumers not just about the production processes and the production conditions, but also in a larger sense about the entire value chain from which a product originates. ${ }^{72}$ There are, however, several limitations of VSS in providing information on risk management and value chain conditions that consequently narrow down their support of firms' compliance with HRDD obligations. This is not problematic per se, but it should not mislead the actors involved in considering VSS as capable, for example, of overlapping fully with EU firms' HRDD responsibilities - covering the entire value chain and the entire spectrum of human rights. VSS do allow downstream companies to acquire information about various aspects of their value chains and directly implement and operationalise corporate due diligence policies and management processes, but only in relation to the human rights risks and for the parts of the value chain addressed by

\footnotetext{
71 Thorlakson et al, supra, note 42.

72 HE Eller, "Private governance of global value chains from within: lessons from and for transnational law" (2017) 8 Transnational Legal Theory 321.
} 
a scheme. ${ }^{73}$ Section IV.1 illustrates the different levels of human rights coverage across different value chain entities. Standards often cover risks at the production stage and not at other levels of the value chain (for which an additional assessment would be needed). Section IV.2 elaborates on the different requirements applicable to certified and noncertified members of a VSS. Section IV.3 discusses the application of certification requirements outside certified production and mass balance models where certified and non-certified materials are mixed in the value chain. These would not contribute to guaranteeing full value chain transparency, where required, and generally guaranteeing that the products sourced are in fact not connected to social and environmental harm.

\section{Varying levels of human rights coverage at different value chain tiers}

As HRDD responsibilities include all possible human rights potentially affected by business operations, ${ }^{74}$ it must be clear - in the first place to firms - that VSS may have a narrower human rights scope. The full range of human rights potentially impacted by a firm is broader, but VSS address a narrower set of social and environmental concerns. For example, FSC does not generally refer to all human rights in its Principles and Criteria but, as its focus lies on forest operations, it covers human rights that can be affected by forest management operations such as workers', customary, community, and Indigenous Peoples' rights. ${ }^{75}$ Other schemes, however, fail to include human rights that would be very relevant in the context of forest management. For example, the Sustainable Forestry Initiative (SFI), a North American scheme recognised under PEFC (an industry-driven umbrella organisation of forest certifications), does not require free, prior and informed consent for forest operations affecting Indigenous Peoples' lands and rights. ${ }^{76}$

The variety of substantive requirements of private standards is also visible in the environmental criteria underpinning issues such as deforestation. The approach suggested by the EU Parliament is to guarantee protection of all natural forests and natural ecosystems, regardless of the legality of conversion under requirements applicable in the country of origin. Natural forests and ecosystems are not defined in the proposal (the initial draft by the Rapporteur used definitions from the Accountability Framework Initiative), ${ }^{77}$ and neither is a cut-off date separating permissible from impermissible deforestation established. Given their wide differences, it is, however, unlikely that all of the current schemes could meet a

\footnotetext{
73 See ISEAL (2020) Corporate due diligence, sustainability standards and certification. Insights and reflections on integrating voluntary sustainability standards into corporate due diligence policies. ISEAL Briefing Note; available at $<$ https://www.isealalliance.org/sites/default/files/resource/2020-01/Due-Diligence-Briefing-Note_ISEAL_01-2020_1. pdf $>$.

74 UN Office of the High Commissioner for Human Rights (2012) The corporate responsibility to respect human rights. An interpretative guide, 13.

75 FSC (2019) FSC support to respect for human rights, p 3.

76 D Judge-Lord, CL McDermott and B Cashore, "Do private regulations ratchet up? How to distinguish types of regulatory stringency and patterns of change" (2020) 33 Organization \& Environment 96.

77 Draft report with recommendations to the Commission on an EU legal framework to halt and reverse EU-driven global deforestation (2020/2006(INL)) ENVI_PR(2020)65235, p 11.
} 
future EU definition. For example, PEFC employs the Food and Agriculture Organization's (FAO) definition of "forest", which does not refer to the notion of a natural forest or ecosystem and allows for conversion under "justified circumstances", with a 2011 cut-off date. ${ }^{78}$ The Roundtable on Responsible Soy (RTRS) prohibits legal and illegal conversions of critical biodiversity hotspots after 2009 and conversion of natural forests that occurred after June $2016 .{ }^{79}$ Schemes such as FSC and RSPO refer instead to the concepts of high-conservation-value areas and highcarbon-stock forests. ${ }^{80}$

Furthermore, it should be clear that most - if not all - of the requirements of VSS apply to the levels of harvest, plantation and unit of production. A comparative study of FSC and PEFC principles and criteria and chain of custody requirements ${ }^{81}$ concluded that the forest management standards applicable to forest units are rather well aligned with the ILO Fundamental Convention, the UNGPs and the OECD Guidelines (although not so much with respect to the chapters on employment, industrial relations and the environment of the OECD Guidelines for multinational enterprises). These requirements are assessed by third-party auditors. However, where certification may require the entire value chain to be certified in various forms of chain of custody certification, intermediary entities in agricultural value chains, such as traders, mills, plants and processing facilities, are rarely subject to requests to comply with requirements concerning environmental impacts and human rights.

For PEFC and FSC, chain of custody requirements include only compliance with the ILO Conventions and are limited to a self-declaration of compliance by firms. ${ }^{82}$ Only a few VSS have broad human rights coverage applicable in their chain of custody certification. FSC recently incorporated core labour standards into the chain of custody audit requirements. ${ }^{83}$ The expansion of human rights considerations in chain of custody requirements allows downstream entities sourcing FSC-certified products to receive assurance in the context of their human rights responsibilities that there is a low risk of at least certain human rights violations in the intermediary value chain tiers. In a similar manner, social and environmental requirements have been introduced in Rainforest Alliance's 2020 version of its value chain standards. ${ }^{84}$ As it will be seen in the next section, VSS are including human rights and HRDD requirements that apply to all Members. This also affects intermediary entities in the value chain that are certified under chain of custody standards.

Scheme managers consider that the purpose of chain of custody standards is to guarantee the credibility of sustainability claims through provisions on how to handle products. Human rights issues are not considered as necessary because they perceive

\footnotetext{
78 PEFC (2018) PEFC benchmark standard on sustainable forest management - requirements, Appendix 1. PEFC ST 1003:2018.

79 RTRS (2016) RTRS standard for responsible soy production. Version 3.0, Art 4.4.2.

80 RSPO (2018) Principles and criteria for the production of sustainable palm oil, criteria 7.7 and 7.12.

81 R Kusumaningtyas, "Labour rights and human rights in forest certification standards: an analysis of FSC and PEFC adherence to the UN Guiding Principles, ILO Fundamental Conventions and OECD Guidelines" (Profundo, 2019).

82 FSC Chain of Custody Certification FSC-STD-40-004 V3-0, Art 1.3.

83 Interview with scheme manager: <https://fsc.org/en/current-processes/incorporating-the-fsc-core-labourrequirements-into-the-coc-standard $>$.

84 RA (2020) Sustainable agriculture standard: supply chain requirements.
} 
risk to lie mostly at the farm level. ${ }^{85}$ As hinted at above, divergence in requirements between those applicable to producers and other value chain entities such as mills and processors is not per se problematic for a downstream entity to which HRDD obligations apply or the intermediary entity that has its own HRDD responsibilities as long they assess and mitigate through their own due diligence possible adverse impacts occurring there. To legislators considering the employment of standards in legislation or their recognition, it should be clear that VSS coverage of risks in the various value chain tiers is often uneven.

Another crucial issue, intimately connected with access to information in risk management, is value chain transparency. As HRDD requires assessing impacts throughout a value chain, it is essential that firms have tools to acquire a clear, full picture of their entire business relations and relevant profiles of social and environmental risks at each value chain tier. The OECD-FAO Guidance - the international standard for responsible agricultural value chains - recommends that all upstream suppliers implement physical segregation and traceability. Downstream enterprises such as retailers and manufacturers are required to be able to identify their upstream suppliers and the sourcing areas of their upstream sub-suppliers. ${ }^{86}$ Complete physical segregation, especially of smallholder crops such as cocoa and palm oil, is very complex if not downright impossible without major changes in how value chains operate aimed at segregating compliant and non-compliant products. Downstream firms are, in fact, hardly in the position to claim that they are sourcing harm-free commodities.

While full segregation and identity-preserved systems are possible - but also much more costly to implement - VSS typically use mass balance requirements. These are procedural and certificate-based systems that allow buyers to purchase certified products from certified producers but then receive products mixed with not-certified produce, albeit from the same country or region. ${ }^{87}$ In light of this system, producers are not in the position to claim that $100 \%$ of a product's content is "sustainable" (eg that the entirety of the cocoa used in a chocolate bar is deforestation and child-labour free). Arguably, the situation would differ if EU legislation were to require certainty about possible connections to value chain harms, or even full value chain traceability.

The European Parliament resolution on deforestation goes in this direction, as it requires full traceability. In addition, and in line with the policy goal of preventing those products connected with harms such as deforestation from find their way into the EU, it also provides that certification schemes can only be used where they grant certification to products with $100 \%$ certified content. ${ }^{88}$ These requirements would not only be problematic for VSS mass balance systems, which would have to be turned into full traceability systems with adequate segregation; VSS schemes that grant a certificate to products also containing non-certified material would similarly raise concerns in the context of EU legislation. These certificates allow labelling, for

85 Interview with scheme manager.

86 OECD/FAO, OECD_FAO Guidance for Responsible Agricultural Value Chains (Paris, OECD Publishing 2016) p 32 .

87 <htps://www.rainforest-alliance.org/faqs/what-is-mass-balance-sourcing $>$.

88 (2020/2006(INL)), p 32. 
example, of products derived from timber (such as paper or furniture) to be certified as sustainable against the scheme's criteria even when only a share of their content in fact originates from certified sources. ${ }^{89}$

\section{Certified and non-certified Members of a VSS}

A firm's membership in a VSS does not say much about its human rights impacts and compliance with HRDD requirements. Requirements for non-producing and noncertified VSS members - often downstream retailers and manufacturers - have been considerably lower than those applicable to certified producers in order to attract downstream firms to participate. ${ }^{90}$ At least some VSS introduced stricter membership requirements in order to make applicable certain key aspects of the standards (such as human rights compliance) to all certified and non-certified members. Compliance with these provisions by non-certified Members, where present, is not assessed via third-party auditing. It is the VSS organisation itself that verifies through internal risk management procedures - also triggered by third-party complaints - whether a member is in compliance. Procedures and effectiveness in monitoring and enforcement may thus vary greatly. Membership in a VSS by a firm with future HRDD obligations such as an EU producer should thus not be equated with HRDD compliance, even when a scheme has specific requirements on HRDD policies and processes.

For example, FSC established a Policy for Association that attempts to extend the impact of FSC standards beyond certified members and forests. According to the Policy, any company associated with FSC (either as a certificate holder, certification body, partner or member) can be disassociated if it is proven that it is responsible, either as a company or because of activities of subsidiary companies or subcontractors, for violations of a series of key requirements. These include illegal logging or trade, destruction of high-conservation-value forests, conversion of forests to plantation, genetically modified organism (GMO) use and violations of traditional rights, human rights and breaches of ILO Core Conventions. ${ }^{91}$ Over time, FSC has attempted to move beyond self-declaration by prospective Members, complemented by stakeholder input, ${ }^{92}$ and towards actively performing a formal due diligence evaluation to assess whether its (prospective) members are directly or indirectly involved in the unacceptable activities listed in the Policy for Association. ${ }^{93}$ Disassociation should take place only in the presence of repeated violations, as the organisation prefers to engage and attempt to address violations through cooperation given that dissociation would not produce any positive outcomes for forests. ${ }^{94}$

\footnotetext{
89 See the FSC Mix label <https://fsc.org/en/fsc-labels $>$. The competing programme PEFC uses a mixed approach for its "PEFC Certified" label: < https://www.pefc.org/for-business/supply-chain-companies/use-the-pefc-label>.

90 Interview with scheme manager.

91 FSC Policy for Association. FSC-POL-01-004 V2-0 EN.

92 ibid, Arts 2.1 and 2.2.

93 FSC (2016) Due diligence evaluation for the association with FSC. FSC-PRO-10-004 V2-0 EN Draft 2.

94 FSC, Processing Policy for Association Complaints in the FSC certification scheme. FSC-PRO-01-009 (V3-0) EN, Art 5.21.
} 
However, revision and expansion of the Policy for Association and the due diligence procedure have been complex, and an attempt to strengthen its enforcement by FSC, as well as clarifying the cases in which an FSC Member through its operations may breach the key criteria, ${ }^{95}$ produced no results and had to be put on hold. ${ }^{96}$ Another revision started in 2020.

Instead of a Policy for Association, Bonsucro established an internal Code of Conduct. Its Code recognises the human rights responsibility of all members in relation to their suppliers. It introduces a requirement applicable to both certified and non-certified members (in Bonsucro, certified members are not farms or farmers, but sugarcane mills) to commit to continuous improvement, respecting human rights, protecting natural ecosystems in the sugarcane value chain, acting to embed this commitment into their operations and communicating progress. ${ }^{97}$ These requirements are aligned with the UNGPs requirements to embed human rights in business operations, to act upon findings of possible human rights adverse impacts, to exercise leverage and to report to the general public. Consistent with the UNGPs' concept of a "direct link" to human rights harms that determines the boundaries of companies' responsibility for respect, the Code also applies to products and services linked by a business relationship to sugarcane production, processing and sourcing. ${ }^{98}$

Candidate and existing Members are expected to perform a social and environmental risk assessment and to identify actions to bring their production, processing and sourcing into compliance with the Code on the basis of the principle of continuous improvement. In itself, the notion of continuous improvement, which is also present in other schemes, can go against HRDD constructs where it does not result in remediation for possible breaches. Bonsucro's Code of Conduct is monitored not through auditing but through an enhanced due diligence process conducted by Bonsucro on its members and on the basis of reports verifying whether a firm presents a high level of risk of generating social and environmental harms. Action plans may be requested in case of noncompliance, with the possibility of referring to Bonsucro's Grievance Mechanism. ${ }^{99}$ The risk assessment process entails online searches, consultations of court records in the country of operation and consultations with other organisations that may possess information about the relevant social and environmental impacts of the perspective Member, as well as online comments by any interested party. ${ }^{100}$ A Committee on Membership then determines the level of risk. Medium or high risk will necessitate corrective actions.

\section{Certified and non-certified products and volumes}

Rarely, VSS in the agricultural domain certify the entire production of a given farm or producer or take into account all relevant agricultural activities of the entities within a

\footnotetext{
FSC, Second Consultation Report on FSC-POL-01-004 V3-0.

$96<$ https://fsc.org/en/current-processes/policy-for-the-association-of-organizations-with-fsc-fsc-pol-01-004>.

97 Bonsucro Code of Conduct, 1.2.

98 Bonsucro Code of Conduct, 2.1.

99 Bonsucro Code of Conduct - Reporting Guidelines.

100 Bonsucro - Membership Application Procedure, point 4.
} 
corporate group. Instead, it is normally a part of the production or specific farms that are certified. From the perspective of a downstream firm in a jurisdiction with (future) HRDD legislation, an HRDD assessment must identify, mitigate and remedy risk all the way upstream. Such a downstream firm could be implicated in adverse impacts where a producer from which they source both certified and non-certified products commits human rights violations in the context of non-certified volumes. Harm could also occur in a production unit or farm whose products are instead not traded or marketed by the downstream firms subject to HRDD obligations. In this case, there would be no "direct link" with adverse impacts through business relations. A similar situation would occur where harm is generated by a subsidiary or associated entity of a firm with which the downstream firm does business but with which there is no direct relation. However, from the perspective of the human rights responsibility of that upstream entity, which could also be subject to its own HRDD obligations, it is uncontroversial that there would be an association with human rights harms.

In certain VSS only, producers for whom a part of their operations is certified must also comply with key certification requirements in other non-certified areas or units of production. As we have seen above, FSC does so via its Policy for Association, which is monitored and enforced by the organisation. RSPO introduced similar but auditable requirements in the 2018 revision of its Principles and Criteria. These requirements mandate the certified entity to have a policy for ethical conduct in all of its business operations and transactions, as well as to respect human rights in the entire value chain. ${ }^{101}$ Firms must implement parallel standards relevant to their entire organisation, which cannot be lower than those in RSPO's criteria. ${ }^{102}$ For intermediary value chain entities such as mills, this approach results in extending certain certification criteria about respecting human rights to the entirety of the sourced volumes, thereby transmitting upstream (ie to the oil palm plantations) a request for certification-compliant (and HRDD-compliant) production.

In addition to these requirements to perform HRDD and engage in continuous improvement monitored by the organisation, Bonsucro is introducing as part of its certification criteria requirements for sugarcane mills and processors on non-certified volumes. Core requirements concerning human rights apply to the entire supply of a mill, including areas that are neither controlled directly nor certified. These areas are often managed by smallholders, whose certification is complex and where environmental and social risks usually lie. ${ }^{103}$ These requirements include enacting sustainability policies to respect human rights, mapping vulnerable stakeholders and assessing risks. These requirements are expected to be implemented in the entire supply area as part of an "active duty involving ongoing due diligence of actual and potential impact", including the production of engagement plans. Auditing is limited to assessing whether sustainability policies and the other requirements are into place. ${ }^{104}$ These new criteria could expand the reach of human rights standards to

\footnotetext{
101 RSPO (2018) Principles and Criteria, Arts 1.2 and 4.1.

102 RSPO Code of Conduct, Art 3.2.

103 Interview with certification manager.

104 Bonsucro Draft Production Standard Version 5, Criteria 1.1, available at <http://www.bonsucro.com/wp-content/ uploads/2020/05/Bonsucro-Production-Standard-V5.1.pdf >.
} 
non-certified production as part of the HRDD responsibility of the mill. The new standard would thus acknowledge that mills' responsibilities (as derived from the UNGPs) extend beyond certified production and include all entities to which they are directly linked via their sourcing activities. In addition, this approach would align with the broad HRDD requirements. Provided that monitoring through audit is effective, a firm based in a jurisdiction with HRDD obligations would receive evidence of low risk of human rights impacts during production when purchasing from certified mills products derived from sugarcane processing.

Standards focusing on GMO use such as ProTerra often require mills and processors that employ inputs from farms that are not certified to design and implement value chain control systems to ensure that the relevant core indicators in the domain of GMOs, but also of social and environmental sustainability, are met. ${ }^{105}$ While this requirement aims mainly at avoiding the commingling of GMO and non-GMO materials, where human rights requirements are monitored closely, the standard also potentially covers the entire human rights responsibilities of the mills towards the farms to which they are directly linked. ${ }^{106}$ In this way, as with the other examples discussed in this section, compliance with a VSS by a farm or processor can indicate to a downstream entity evidence of low risk against certain social and environmental criteria for the entirety of their production.

\section{Collaborative approaches in Risk mitigation AND REMEdiation}

Human rights violations and social conflicts within value chains are likely to endure without collaborative approaches among all business and non-business stakeholders involved. ${ }^{107}$ HRDD as prescribed in the UNGPs also requires collaboration between downstream firms and upstream entities in actively mitigate risks of human rights impacts. ${ }^{108}$ It is thus essential that firms do not merely engage in risk-averse conduct such as disengaging from non-compliant suppliers nor avoid altogether high-risk areas and suppliers - which may in fact aggravate the situation for human rights holders. ${ }^{109}$ This idea aims to ensure that change on the ground actually takes place and that a responsibility/obligation to respect human rights does not create segregated markets where compliant products are sold in Western markets and non-compliant ones are sold elsewhere. Collaboration is also essential with non-business stakeholders and human rights holders for ensuring the mitigation of impacts and remediation where adverse impacts occur.

105 See, for example, ProTerra Standard for Social Responsibility and Environmental Sustainability Version 4.1 September 25, 2019, point 1.2.

106 Interview with scheme manager.

107 J Rotter, P-E Airike and C Mark-Herbert, "Exploring political corporate social responsibility in global value chains" (2014) 125 Journal of Business Ethics 581.

108 Shift Project (2013) Using leverage in business relationships to reduce human rights risks (November 2013), available at $<$ https://www.shiftproject.org/resources/publications/leverage-business-relationships-reduce-humanrights-risk/>.

109 UN Office of the High Commissioner for Human Rights (2012) The corporate responsibility to respect human rights. An interpretative guide. HR/PUB/12/02, 50-51. 
Engagement can take forms such as committing to higher wages or purchase volumes, longer-term contractual relations and active investment facilitated by downstream firms to improve working, social and environmental conditions upstream so that adverse impacts are less likely. ${ }^{110}$ In practice, this principle is difficult to operationalise as companies may lack the knowledge and incentives to actively engage, even in the presence of possible legislation requiring engagement and a cooperative approach to human rights value chain impacts, ${ }^{111}$ or international standards stressing the importance of industry-wide cooperation for eradicating human rights and environmental harms. ${ }^{112}$ Engagement may be burdensome and may require costsharing and even direct financing from downstream to upstream entities in some cases. The allocation of costs associated with human rights responsibilities remains unclear and contestable. ${ }^{113}$ HRDD also requires that human rights violations, where they occur and emerge, are remedied and the status quo is restored, a requirement that is arguably more easily fulfilled through collaboration, including at a sectoral level. ${ }^{114}$

A few VSS have established forms of collaboration between retailers and producers that contribute to operationalising this UNGPs notion, which is also reflected in the risk mitigation obligations contained in the EU Parliament's proposals. Schemes are attempting to bind retailers to the amount of certified materials that they purchase. Increased commitment determines a steadily growing demand for certified products that can thus allow producers to undertake the necessary investment to comply with the standards and consequently lower social and environmental risks. ${ }^{115}$ Longer, predictable and stable contractual relations are also considered a best practice of responsible business conduct. ${ }^{116}$ RSPO introduced in 2019 a "Shared Responsibility" policy that is particularly relevant for non-certified Members. "Shared Responsibility" defines the precise collective commitments for collaboration and accountability that are needed to transform palm oil markets towards responsible outcomes. ${ }^{117}$

An obligation is also introduced for Members to support small farmers, raise awareness and offer training. The most salient aspect arguably concerns the identification of volume targets for buyers. Manufactures and retailers that are RSPO Members commit to purchasing in the first year of implementation an extra $15 \%$ of certified palm oil, while traders and processors have a $2 \%$ target. Such a commitment from downstream firms matches the commitment from farms to comply with more stringent RSPO

\footnotetext{
110 Shift Project (2013) Bringing a Human Rights Lens to Stakeholder Engagement. Shift Workshop Report No. 3 (August 2013), available at <https://shiftproject.org/wp-content/uploads/2013/08/Shift_stakeholderengagement2013. pdf $>$.

111 See, for example, Conflict Minerals Regulation, Arts 4(d) and 4(e); OECD Guidance on Conflict Minerals, Annex II.

112 For agricultural products, see OECD/FAO, supra, note 86, 23 and 32.

113 MC Schleper, C Blome and DA Wuttke, "The dark side of buyer power: supplier exploitation and the role of ethical climates" (2017) 140 Journal of Business Ethics 97.

114 UNGPs Principle 22.

115 C Gallemore, A Guisinger, M Kruuse, D Ruysschaert and K Jespersen, "Escaping the 'teenage' years: the politics of rigor and the evolution of private environmental standards" (2018) 152 Ecological Economics 83.

116 OECD (2017) OECD due diligence guidance for responsible supply chains in the garment and footwear sector, p 74.

117 RSPO Shared Responsibility task force. Shared Responsibility requirements and implementation, p 7.
} 
requirements concerning no deforestation, development on peat and human rights violations. ${ }^{118}$ Members will have to report their purchase commitments, which are independently verified and included in the audit requirements for Members certified under the Chain of Custody Standards. Systems for sanctions and incentives are currently being discussed and developed, as well as the provision of financial contributions for Members to be directly used to offer various forms of support to smallholders towards certification. ${ }^{119}$

A similar approach aiming at spreading the risks, costs and benefits of sustainability transformations more evenly between producers and buyers was introduced by RA-UTZ in the 2020 standards revision. The new standard introduced a "sustainability differential" (ie a price premium to certified producers above market prices) to recognise farmers' sustainability efforts and to support the continued uptake of sustainable production. While a price premium is already present in schemes such as Fairtrade, buyers of certified products under RA-UTZ certification are also required to make (and report about) "sustainability investments", which are necessary to enable farmers to comply with production requirements or the cost of auditing and on the basis of investment plans designed by farmers themselves. ${ }^{120}$ Both the sustainability differential and sustainability investment are paid by the first buyer, included in the contract of sale and recorded in RA's traceability system and reports. ${ }^{121}$ Bonsucro's Implementation Guidelines of the 2020 Code of Conduct also require continuous commitments and improvements. Mills, intermediaries and end users may demonstrate improvements by sourcing an increasing percentage of certified material and engaging with suppliers in supporting them towards certification. $^{122}$

Schemes contemplating these forms of across-the-chain engagement could contribute to risk mitigation where they enable social and environmental transformations impacting on some of the (economic) conditions that eventually result in human rights breaches and adverse environmental impacts. The mitigation of environmental risks across schemes, however, is more orientated towards the protection rather than restoration of forests and ecosystems. ${ }^{123}$ Ultimately, the possibility of a fairer distribution of the costs and benefits of sustainability brings about much-needed elements of social justice that are endemically lacking in global value chain relations. ${ }^{124}$ These programmes are, however, only in the process of being implemented, and their operation, effectiveness and enforcement remain uncertain to date.

Some VSS also provide operation-level grievance mechanisms and remediation processes. It remains to be seen whether these are effective in terms of both process

118 <https://rspo.org/news-and-events/news/what-are-the-new-shared-responsibility-rules $>$.

119 RSPO Shared Responsibility task force. Shared Responsibility requirements and implementation, p 16.

120 RA, 2020 Sustainable Agriculture Standards, p 8.

121 RA, Annex 6 - Traceability and Shared Responsibility, pp 16-17.

122 Bonsucro Code of Conduct - Implementation Guidelines, Point B.

123 V Ingram, J Behagel, A Mammadova and X Verschuur, "The outcomes of deforestation-free commodity value chain approaches" (2020) Netherlands Environmental Assessment Agency (PBL) Discussion Paper, 4-5, available at $<$ https://www.wur.nl/en/project/Outcomes-of-deforestation-free-commodity-value-chain-approaches.htm $>$.

124 S Ponte, Business Power and Sustainability in a World of Global Value Chains (London, Zed Books 2019) pp 20-21. 
and outcome and are legitimate, accessible, predictable, equitable and transparent as prescribed by UNGP Principle 31. A recent study identified various shortcomings in the establishment and operation of the grievance mechanisms offered by schemes, including cost barriers, power imbalances between the parties, a lack of transparency and confidentiality and very limited awareness of the possibility of filing a complaint among affected communities. ${ }^{125}$ As HRDD legislation will likely also require the establishment of grievance mechanisms, those offered by VSS will likely have to be improved and aligned with the requirements specified in EU legislation.

Remediation for social and environmental harms has been introduced in recent iterations of both RA and RSPO standards. Since 2014-2015, RSPO requires certified Members that engaged in non-compliant land clearance for plantation or other facilities after the 2005 cut-off date to use remediation and compensations mechanisms. Members will have to designate areas under protection to offset areas that they previously converted. ${ }^{126}$ If land-use change affected the human rights of affected communities, social remediation and compensation plans must be negotiated with the relevant right holders. ${ }^{127}$ In RA, in line with HRDD, a separate protocol on remediation was introduced requiring mandatory remediation in connection with human rights risk assessment, offering guidance on how to effectively remediate any human rights violations. ${ }^{128}$ In addition, a strong remediation Guidance is included in the Accountability Framework Initiative, ${ }^{129}$ which, however, only offers definitions and is not certifiable, and it was developed by building on the UNGPs requirements. ${ }^{130}$

\section{Conclusion}

HRDD generates a demand for across-the-chain social and environmental risk management tools. Mandatory due diligence will further strengthen the demand from firms for HRDD-compliant tools. This contribution addressed how key HRDD constructs are operationalised by VSS, in view of understanding the extent to which standards are aligned with the substantive human rights and value chain scope of the UNGPs and future EU regulation in this area. VSS may complement various components of due diligence systems, particularly in the acquisition of information on compliance with HRDD requirements, as a tool for traceability and as possible mitigation measure depending on the requirements of the scheme. Certification may provide an extent of assurance that certain products present negligible or low social and environmental risk. The role of VSS in future HRDD legislation should also recognise, in line with the EU Parliament proposal, their possibility of being

\footnotetext{
125 MSI Integrity (2020) Not fit-for-purpose: The grand experiment of multi-stakeholder initiatives in corporate accountability, human rights and global governance, 167-68.

126 Interview with certification manager.

127 RSPO Remediation and Compensation Procedure (RaCP) Related to Land Clearance Without Prior High Conservation Value (HCV) Assessment RSPO-PRO-T02-001 V2.0, p 15.

128 RA, Annex 4 - Rainforest Alliance Remediation Protocol v. 1.

129 Accountability Framework Initiative (2020) Operational Guidance on Environmental Restoration and Compensation; Accountability Framework Initiative (2020) Operational Guidance on Remediation and Access to Remedy.

130 Interview with certification manager.
} 
employed only when in line with strict governance criteria apprising independence from industry, the inclusion of social and environmental interests in standard-setting, independent third-party auditing, disclosure of auditing reports, transparency at all stages and openness.

To legislators considering the employment of voluntary standards in legislation, or even their formal recognition, it should, however, be clear that VSS coverage of social and environmental harms varies greatly in respect to human rights addressed, the definition of deforestation-related issues and the value chain tiers subject to auditing and certification. Assuming that auditing is reliable, schemes could be used by the firms to which HRDD obligations apply to serve as rebuttable evidence of low risk, but only for the limited types of harms and value chain entities covered by that specific scheme. These may not be easy to identify, and they require delving deep into a scheme's requirements and operation. For other harms, and for other value chain relations not covered by that VSS, firms will have to perform separate due diligence. Some private schemes have nonetheless expanded their application of key requirements to non-certified production and non-certified members in order to better account for the human rights responsibilities of entities at different levels of the value chain. This arguably allows schemes to cover relevant risks for a broader number of entities to which they are linked in their value chains and, potentially, to better fit into the HRDD systems of downstream firms marketing in jurisdictions with HRDD legislation.

By strengthening their efforts in the provision of collaborative tools between firms at different levels in the value chain, VSS not only provide standards, but also offer fora for engagement aimed at risk mitigation, remediation and, generally, for sharing the costs of social and environmental compliance required by HRDD. These functions can hardly be considered as regulatory, nor directly connected to conventional risk management, but they are nonetheless relevant for HRDD and its risk mitigation requirements. By not just certifying whether social and environmental criteria are met, at least some VSS are designing ways to tackle some of the structural economic drivers of social and environmental violations. While the effectiveness of these programmes remains to be seen, they testify to the broadened intervention of private regulators in establishing cooperative platforms between retailers in consuming markets and producers often in the Global South ${ }^{131}$ that mirror and possibly complement those established by public institutions. $^{132}$

\footnotetext{
131 N Estrada-Carmona, AK Hart, FAJ DeClerck, CA Harvey and JC Milder, "Integrated landscape management for agriculture, rural livelihoods, and ecosystem conservation: An assessment of experience from Latin America and the Caribbean" (2014) 129 Landscape and Urban Planning 1.

132 See the Commission Initiative for Sustainable Cocoa: <https://trade.ec.europa.eu/doclib/press/index.cfm?id= $2185>$.
} 